\title{
Pituitary tumor-transforming 1 expression in laryngeal cancer and its association with prognosis
}

\author{
KUNPENG MA ${ }^{1}$, LIMIN MA ${ }^{2}$ and ZHAOCHENG JIAN ${ }^{3}$ \\ ${ }^{1}$ Department of Otorhinolaryngology, Affiliated Hospital of Weifang Medical University, Weifang, Shandong 261031; \\ ${ }^{2}$ Department of Plastic Surgery, Plastic Surgery Hospital of Weifang Medical University, Weifang, Shandong 261041; \\ ${ }^{3}$ Department of Vascular Interventional Radiology, Affiliated Hospital of Weifang Medical University, \\ Weifang, Shandong 261031, P.R. China
}

Received August 17, 2016; Accepted February 12, 2018

DOI: $10.3892 / \mathrm{ol} .2018 .8745$

\begin{abstract}
The purpose of the present study was to investigate the association between the expression of pituitary tumor-transforming 1 (PTTG1) and the expression of matrix metalloproteinase (MMP)-2 and MMP-9 in laryngeal carcinoma tissues, and to elucidate the association between PTTG1 expression and the prognosis of patients with laryngeal cancer. Immunohistochemical staining was used to detect PTTG1 expression in laryngeal cancer and normal tumor-adjacent laryngeal tissues. Western blotting was used to determine the levels of PTTG1 and MMP-2 and -9 in laryngeal carcinoma tissues and to assess their correlation. In addition, the associations between PTTG1 expression and the clinical parameters of laryngeal cancer and patient survival were determined. The immunohistochemistry results revealed that the positive expression rates of PTTG1, MMP-2 and MMP-9 in the laryngeal cancer tissues were significantly higher than those in the carcinoma-adjacent normal laryngeal tissues (all $\mathrm{P}<0.05$ ). In addition, expression levels of PTTG1, MMP-2 and MMP-9 were significantly associated with lymph node metastasis, histological grade and clinical stage $(\mathrm{P}<0.05)$. Furthermore, the levels of PTTG1 were positively correlated with the levels of MMP-2 and MMP-9 in laryngeal cancer tissues $(\mathrm{P}<0.05)$. In summary, the expression levels of PTTG1, MMP-2 and MMP-9 are closely associated with the biological behaviors of laryngeal cancer tissues, showing that they serve important roles in the occurrence and development of laryngeal cancer, and may be useful as biological
\end{abstract}

Correspondence to: Dr Kunpeng Ma, Department of Otorhinolaryngology, Affiliated Hospital of Weifang Medical University, 2428 Yuhe Road, Kuiwen, Weifang, Shandong 261031, P.R. China

E-mail: maxiaofei918@126.com

Key words: pituitary tumor-transforming 1, matrix metalloproteinase 2, matrix metalloproteinase 9, laryngeal cancer, invasion, metastasis, prognosis indicators of laryngeal tissue invasion, metastasis and patient prognosis.

\section{Introduction}

Laryngeal cancer is a common malignant tumor of the head and neck, with the main pathological type being squamous cell carcinoma. It accounts for $2.4 \%$ of new occurrences of malignant tumors worldwide (1). Due to environmental changes and the role of carcinogenic factors, the incidence of laryngeal cancer has increased in recent years (2). At present, laryngeal cancer treatment predominantly involves surgery and radiation therapy, but may also involve antitumor drug therapy and gene therapy. Although early laryngeal cancer treatment is effective, clinical treatment failure and poor prognosis are frequent in cases of advanced laryngeal cancer involving invasion and metastasis (3). Therefore, it is essential to improve the treatment of patients with laryngeal cancer by exploring effective detection and prognostic indicators and determining optimal therapeutic strategies.

Pituitary tumor-transforming 1 (PTTG1) was first isolated from rat pituitary tumor cells in 1997 (4). The study found that PTTG1 is a cancer-causing gene (4). Furthermore, its overexpression has been shown to be involved in inducing cell transformation in nude mice and tumor formation in vitro, and PTTG1 expression levels are associated with tumor invasion (5). PTTG1 is an important biological marker of cancer cells and may be considered an independent predictor of overall survival as well as tumor differentiation, metastasis, and progression. It is considered to be a key gene associated with tumor metastasis (6) and with the prognosis of malignant head and neck tumors (7).

Matrix metalloproteinase (MMP)-2 and MMP-9 of matrix metalloproteinase were closely associated with the occurrence, development, infiltration and metastasis of laryngeal cancer (8). In the present study, immunohistochemistry and western blotting were used to detect PTTG1, MMP-2 and MMP-9 expression in laryngeal cancer tissues. In addition, the correlation of PTTG1 with MMP-2 and MMP-9 expression in laryngeal cancer, as well as its association with laryngeal cancer occurrence, development and metastasis, were investigated in order to provide a novel basis for 
prognostic judgment and targeted therapy for patients with this malignancy.

\section{Materials and methods}

Materials. A total of 210 patients with laryngeal squamous cell carcinoma, who were treated between January 2004 and December 2008 in the Otolaryngology Department of the Affiliated Hospital Weifang Medical University (Weifang, China), were included. This comprised a total of 199 men and 11 women, with an age range of 39-80 years and a mean age of 62.3 years. There were 48 patients with well-differentiated tumors, 66 patients with moderately differentiated tumors, and 96 patients with poorly differentiated tumors. Lymph node metastasis was present in 117 patients, while 93 patients had no metastasis. According to the tumor-node-metastasis staging system (Union for International Cancer Control, 2010) (9), 95 cases were stage I-II and 115 cases were stage III-IV. There were 82 cases of supraglottic tumors, 117 cases of glottic tumors, and 11 cases of subglottic tumors. None of the patients received radiotherapy or chemotherapy prior to surgery. Patient characteristics are summarized in Table I. In addition to the laryngeal cancer tissues, 210 samples of normal laryngeal tissues adjacent to the carcinoma were taken from the mucosa $5 \mathrm{~cm}$ from the tumor edge for use as the control group. Laryngeal cancer tissues, normal laryngeal tissues and lymph node metastasis were all confirmed by hematoxylin and eosin staining. Survival time was calculated from the date of surgery to the date of the last follow-up or the date of mortality of patients who succumbed to tumor recurrence or metastasis. The follow-up period ranged from 7 to 60 months, with an average of 39.5 months. The study was designed so as to comply with the ethical standards outlined by the Declaration of Helsinki (1975).

The study protocol was approved by the Ethics Committees of the Affiliated Hospital of Weifang Medical University, and all participants provided written informed consent.

Main reagents. The rabbit polyclonal antibodies against PTTG1 was purchased from Santa Cruz Biotechnology, Inc. (Dallas, TX, USA; cat. no. SC-56207). The goat anti-rabbit IgG (cat. no. ZB-2010), Ra (cat. no. TA-09), MMP-2 (cat. no. ZA-0331), MMP-9 (cat. no. ZA-0562) and bovine serum albumin (cat. no. ZLI-9027) were purchased from Beijing ZhongShan Golden Bridge Biological Technology Co., Ltd. (Beijing, China). The SP-kit, containing endogenous peroxidase blocker, normal goat serum, biotin-labeled goat anti-mouse/rabbit IgG polymer and horseradish peroxidase working solution was purchased from Beijing ZhongShan Golden Bridge Biological Technology Co.,Ltd.(Beijing, China; cat. no. SP-9000). The ECL kit was purchased from Beyotime Institute of Biotechnology, Haimen, China. (cat. no. P1008).

Immunohistochemical analysis. The expression of PTTG1, MMP-2, and MMP-9 in laryngeal cancer normal cancer-adjacent laryngeal tissue were determined using an immunohistochemical avidin-biotin peroxidase complex method, according to the manufacturer's protocols (Santa Cruz Biotechnology, Inc. and Beijing ZhongShan Golden Bridge Biological Technology Co., Ltd., Beijing, China). Specimens of laryngeal cancer tissues and normal cancer-adjacent laryngeal tissues were fixed with formalin, embedded in paraffin, and cut into $4-\mu \mathrm{m}$-thick slices. Samples were baked at $68^{\circ} \mathrm{C}$ for $20 \mathrm{~min}$. A conventional xylene dewax for 25 min and dehydration with graded alcohol for 10 min was performed. Endogenous peroxidase activity was blocked using $3 \% \mathrm{H}_{2} \mathrm{O}_{2}$ for $10 \mathrm{~min}$. Antigen retrieval was carried out by boiling samples in $0.01 \mathrm{M}$ citric acid buffer ( $\mathrm{pH}$ 6.0) at $95^{\circ} \mathrm{C}$ for $15-20 \mathrm{~min}$, cooling for $>20 \mathrm{~min}$ and washing with PBS. Blocking was performed with goat serum at $37^{\circ} \mathrm{C}$ for $20 \mathrm{~min}$. Primary antibodies were incubated at $4^{\circ} \mathrm{C}$ overnight. PTTG1 (SC-56207; dilution, 1:200; Santa Cruz Biotechnology, Inc., Dallas, TX, USA), MMP-2 (cat. no. ZA-0331; dilution, 1:50) and MMP-9 (cat. no. ZA-0562; dilution, 1:50) were purchased from Beijing ZhongShan Golden Bridge Biological Technology Co., Ltd. This was followed by 3 PBS washes for 5 min each. As a negative control, PBS was used in place of primary antibodies. The biotin-labeled secondary antibody was used at a dilution of 1:100, added dropwise and incubated at $37^{\circ} \mathrm{C}$ for $30 \mathrm{~min}$, followed by three PBS washes lasting 5 min each. Samples were incubated with streptomycin ovalbumin solution labeled with horseradish peroxidase for $30 \mathrm{~min}$ at $37^{\circ} \mathrm{C}$, followed by three PBS washes each lasting $5 \mathrm{~min}$. Following this, the samples were stained with DABcolor (1:100 dilution) at room temperature for 5-10 min, washed with PBS or tap water for $10 \mathrm{~min}$, counterstained with hematoxylin for 2 min, washed with tap water for 10-15 min, conventionally dehydrated, transparent, mounted and examined with a light microscope (magnification, x200 and x400). Known positive laryngeal squamous cell carcinoma sections were used as the positive control, and PBS buffer instead of primary antibody was used as the negative control.

For evaluation, tissues were viewed under a light microscope (Olympus BX46; Olympus Corporation, Tokyo, Japan). Evaluation was performed by a pathologist (Department of Pathology, Affiliated Hospital of Weifang Medical University) with 5 slices in each group, randomly selecting 4 fields of view at a magnification of $x 200$ and $\times 400$. PTTG1-positive laryngeal cancer cells were those that exhibited light brown staining in the cytoplasm and cell membrane. MMP-2 and MMP-9 were expressed in the cytoplasm cells that exhibited tan staining were positive for MMP-2 or -9. A previously published semi-quantitative evaluation method was used (10). The positive staining percentage was divided into 5 levels, assigned a score of $0-4: 0,<10 \%$ of cells positively stained; $1,11-25 \%$ stained; 2, 26-50\% stained; 3, 51-75\% stained; and 4, $>75 \%$ stained. The intensity of positive staining was assigned a score of 0-3: 0, negative; 1 , weak; 2 , medium; and 3 , strong.

The product of the two staining variable scores represented the PTTG1 expression score for each sample: A score of $\geq 6$ was considered high expression, while a score of $<6$ was considered low expression.

Western blot analysis. PTTG1 expression was detected by western blotting of proteins extracted from laryngeal tissues, with reference to the methods reported by Towbin et al (11). Laryngeal cancer and cancer-adjacent normal laryngeal tissues $(50 \mathrm{mg}$ ) were processed with radioimmunoprecipitation assay buffer (Shanghai HuaYi Bi-technology Co., Ltd.) in order to extract total protein. Protein concentration was determined using a bicinchoninic acid assay. Samples of total protein $(20 \mu \mathrm{g})$ were mixed with $5 \mu \mathrm{l}$ of SDS-PAGE loading 
Table I. Expression of PTTG1, MMP-2 and MMP-9 and their associations with clinicopathological features.

\begin{tabular}{|c|c|c|c|c|c|c|c|}
\hline \multirow{2}{*}{$\begin{array}{l}\text { Baseline } \\
\text { characteristic }\end{array}$} & \multirow{2}{*}{$\begin{array}{l}\text { Total } \\
\text { cases }\end{array}$} & \multicolumn{2}{|c|}{ PTTG1 } & \multicolumn{2}{|c|}{ MMP-2 } & \multicolumn{2}{|l|}{ MMP-9 } \\
\hline & & Positive, n (\%) & P-value & Positive, n (\%) & P-value & Positive, n (\%) & P-value \\
\hline Patient sex & & & 0.855 & & 0.255 & & 1.000 \\
\hline Male & 199 & $176(88.44)$ & & $177(88.94)$ & & $175(87.94)$ & \\
\hline Female & 11 & $9(81.82)$ & & $8(72.73)$ & & $10(90.91)$ & \\
\hline Patient age, years & & & 0.673 & & 0.190 & & 0.642 \\
\hline$\geq 55$ & 134 & $119(88.81)$ & & $121(90.30)$ & & $117(87.31)$ & \\
\hline$<55$ & 76 & $66(86.84)$ & & $64(84.21)$ & & $68(89.47)$ & \\
\hline Lymph node metastasis & & & $<0.001$ & & $<0.001$ & & $<0.001$ \\
\hline Present & 117 & $112(95.73)$ & & $114(97.44)$ & & $115(98.29)$ & \\
\hline Absent & 93 & $73(78.49)$ & & $71(76.34)$ & & $70(75.27)$ & \\
\hline Tumor-node-metastasis stage & & & $<0.001$ & & $<0.001$ & & 0.001 \\
\hline $\mathrm{I} / \mathrm{II}$ & 95 & $74(77.89)$ & & $71(74.74)$ & & $76(80.00)$ & \\
\hline III/IV & 115 & $111(96.52)$ & & $114(99.13)$ & & $109(94.78)$ & \\
\hline Tumor differentiation & & & $<0.001$ & & $<0.001$ & & 0.001 \\
\hline Well/moderately differentiated & 114 & $91(79.82)$ & & $92(80.70)$ & & $93(81.58)$ & \\
\hline Poorly differentiated & 96 & $94(97.92)$ & & $93(96.88)$ & & $92(95.83)$ & \\
\hline Tumor location & & & 0.325 & & 1.000 & & 0.948 \\
\hline Supraglottic/glottic & 198 & $176(88.89)$ & & $174(87.87)$ & & $175(88.38)$ & \\
\hline Subglottic & 12 & $9(75.00)$ & & $11(91.66)$ & & $10(83.33)$ & \\
\hline
\end{tabular}

Data were analyzed by $\chi^{2}$ test. PTTG1, pituitary tumor-transforming 1; MMP, matrix metalloproteinase.

buffer (Beyotime Institute of Biotechnology) and heated at $100^{\circ} \mathrm{C}$ for $5 \mathrm{~min}$. The samples were then separated by $8 \%$ SDS-PAGE. Polyvinylidene difluoride membranes were blocked for $2 \mathrm{~h}$ at room temperature with TBST containing $5 \%$ bovine serum albumin, and proteins were electrotransferred onto the membranes at $100 \mathrm{~V}$ for $90 \mathrm{~min}$ at room temperature. The membranes were incubated with primary antibodies [anti-PTTG1 (dilution 1:1,000) and anti- $\beta$-actin (dilution, $1: 2,000)$ ] overnight at $4^{\circ} \mathrm{C}$, then with the horseradish peroxidase-labeled secondary antibody (dilution, 1:1,000)] at $37^{\circ} \mathrm{C}$ for $2 \mathrm{~h}$ prior development with the ECL kit. ImageJ software (version 1.38; National Institutes of Health, Bethesda, MA, USA) was used to read the image reversal pattern of the grey value of the protein bands. The experiment was repeated three times.

Statistical methods. Statistical tests were processed with SPSS 13.0 statistical software (SPSS, Inc., Chicago, IL, USA). A $\chi^{2}$ test was used to analyze the associations between the PTTG1 positive rate and the clinicopathological parameters. A Spearman's rank correlation coefficient $\left(r_{s}\right)$ analysis was used to analyze the correlations between PTTG1, MMP-2 and MMP-9 expressions levels. $\mathrm{P}<0.05$ was considered to indicate a statistically significant difference.

\section{Results}

PTTG1 expression differs between laryngeal cancer tissues and cancer-adjacent normal laryngeal tissues.
Immunohistochemistry revealed that PTTG1 was predominantly expressed in the cytoplasm of laryngeal cancer cells (Fig. 1). The rate of positive expression of PTTG1 among the laryngeal cancer tissue samples was $88.09 \%$ (185/210 patients) (10), whereas the rate among the normal cancer-adjacent tissues was $17.14 \%(36 / 210)$; this difference was statistically significant $\left(\chi^{2}=212.020, \mathrm{P}<0.001\right)$.

The western blot analysis revealed a clear band corresponding to a $68-\mathrm{kD}$ protein. Among the 210 cases, 179 laryngeal cancer tissues exhibited PTTG1 protein expression $(85.23 \%)$, while 53 tumor-adjacent tissues exhibited PTTG1 expression (24.76\%); statistical analysis indicated that PTTG1 protein expression was increased in laryngeal cancer compared with tumor-adjacent normal tissues $\left(\chi^{2}=46.829\right.$, $\mathrm{P}<0.001$; Fig. 2). $\beta$-actin was used as an internal control.

Association of PTTG1, MMP-2 and MMP-9 expression with clinicopathological variables in laryngeal cancer. The PTTG1 positive expression rate in the group of patients with lymph node metastasis $(95.73 \%, 112 / 117)$ was significantly higher than that in the group without lymph node metastasis (78.49\%, 73/93; $\left.\chi^{2}=14.670, \mathrm{P}<0.001\right)$. In addition, the PTTG1 positive rate was higher in the stage III-IV group compared with the stage I-II group $\left(\chi^{2}=5.265, \mathrm{P}<0.001\right)$, and was higher in the poorly differentiated group compared with the group with well/moderately differentiated tumors $\left(\chi^{2}=5.476, \mathrm{P}<0.001\right)$. PTTG1 expression in laryngeal cancer demonstrated no association with patient age or sex, or with tumor site $(\mathrm{P}>0.05$; Table I). 

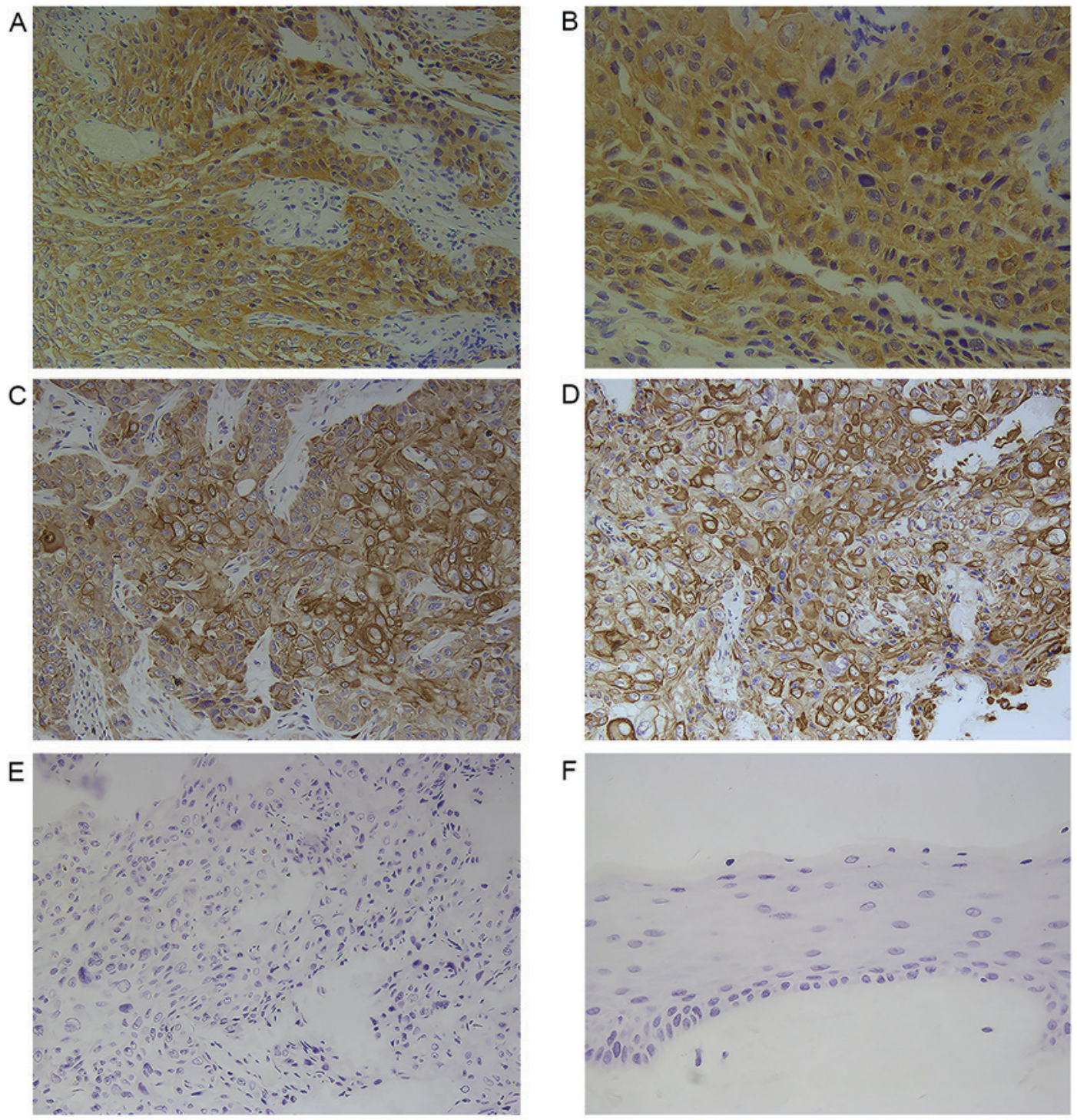

Figure 1. Immunohistochemical staining of PTTG1 and MMP proteins in laryngeal squamous cell carcinoma tissue and adjacent normal laryngeal tissue specimens. Positive PTTG1 immunostaining was predominantly localized in the cytoplasm of cancer cells. (A and B) Positive PTTG1 expression in laryngeal squamous cell carcinoma: magnification, (A) x200 and (B) x400. (C and D) Positive expression of (C) MMP-2 and (D) MMP-9 expression in laryngeal squamous cell carcinoma (magnification, x200). (E) Negative PTTG1 expression in laryngeal squamous cell carcinoma (magnification, x200). (F) Negative PTTG1 expression in normal laryngeal epithelium (magnification, x400). PTTG1, pituitary tumor-transforming 1; MMP, matrix metalloproteinase.

The $\chi^{2}$ test indicated that MMP-2 expression was significantly associated with lymph node metastasis, tumor differentiation degree, and clinical stage $(\mathrm{P}<0.001)$, but was no correlated with patient age or sex, or with tumor site $(\mathrm{P}>0.05)$. Similarly, MMP-9 expression level was significantly associated with lymph node metastasis, tumor differentiation degree, and clinical stage $(\mathrm{P} \leq 0.001)$, but not with the other variables assessed $(\mathrm{P}>0.05$; Table I).

PTTG1 expression is correlated with the expression of MMP-2 and MMP-9 in laryngeal carcinoma. Of the 185 laryngeal cancer cases with positive PTTG1 expression, there were 167 cases with positive MMP-2 expression and 163 cases with positive MMP-9 expression. The Spearman rank correlation analysis indicated that the expression level of PTTG1 was positively correlated with the expression levels of MMP-2 $\left(r_{s}=0.622, P<0.05\right)$ and MMP-9 $\left(r_{s}=0.818, P<0.05\right)$ in laryngeal cancer cells (Table II).

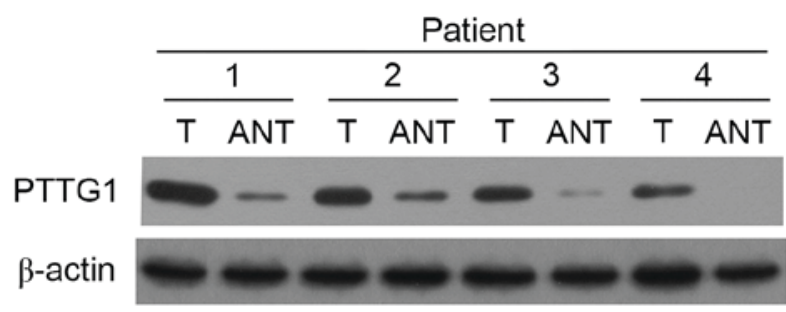

Figure 2. PTTG1 expression in laryngeal cancer tissues and tumor-adjacent noncancerous tissues. PTTG1 protein expression in pairs of T and ANT specimens from the same patients. $\beta$-actin was used as the internal control antibody. A representative image was selected from among the three experiments. PTTG1, pituitary tumor-transforming 1; T, tumor tissue; ANT, adjacent normal tissue.

PTTG1 expression level is associated with postoperative survival rate in laryngeal cancer. Kaplan-Meier analysis and log-rank test results showed that the median survival 
Table II. Correlation of PTTG1 expression with MMP-2 and MMP-9 levels.

MMP-2

MMP-9

\begin{tabular}{|c|c|c|c|c|c|c|c|c|c|c|c|c|}
\hline \multirow{2}{*}{$\begin{array}{l}\text { PTTG1 } \\
\text { level }\end{array}$} & & \\
\hline & Level & & & & $\mathrm{r}_{\mathrm{s}}$ value & P-value & Level & & & & $\mathrm{r}_{\mathrm{s}}$ value & P-value \\
\hline & 0 & 1 & 2 & 3 & & & 0 & 1 & 2 & 3 & & \\
\hline 1 & 1 & 17 & 21 & 17 & 0.622 & $<0.05$ & 9 & 13 & 23 & 11 & 0.818 & $<0.05$ \\
\hline 2 & 13 & 25 & 29 & 18 & & & 9 & 27 & 26 & 23 & & \\
\hline 3 & 4 & 13 & 20 & 7 & & & 4 & 12 & 22 & 6 & & \\
\hline
\end{tabular}

Data are presented as the number of patients and were analyzed according to Spearman's rank correlation coefficient $\left(\mathrm{r}_{\mathrm{s}}\right)$. PTTG1, pituitary tumor-transforming 1; MMP, matrix metalloproteinase.

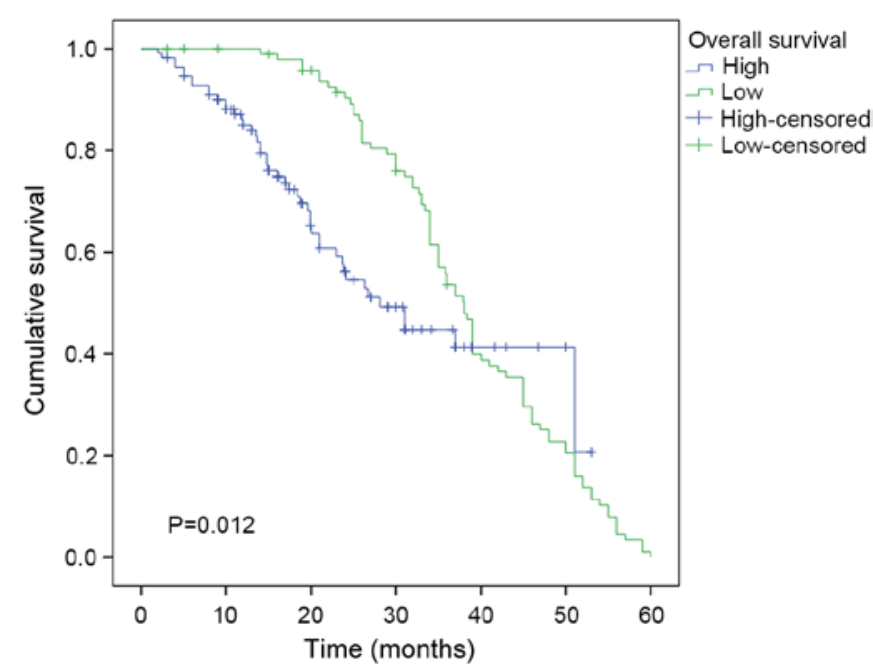

Figure 3. Kaplan-Meier analysis of overall survival in patients with laryngeal cancer according to low PTTG1 expression $(n=89)$ and high PTTG1 expression $(n=112)$. P-value was calculated by log-rank test and indicated a statistically significant difference. PTTG1, pituitary tumor-transforming 1.

time in the group of patients with low PTTG1 expression was 38 months, whereas it was 28.1 months in the group of patients with high PTTG1 expression $(\mathrm{P}<0.05$; Fig. 3$)$. The survival rate of patients with low PTTG1 expression was significantly higher than that of patients with high PTTG1 expression; thus, the expression of PTTG1 appears to be negatively correlated with the overall survival rate of patients with laryngeal cancer.

In addition, when patients were subgrouped according to stage of laryngeal cancer, the overall survival rates were significantly shorter in patients with high vs. low PTTG1 expression in the stage I/II subgroup $(n=95 ; P=0.014 ;$ Fig. 4$)$ and in the stage III/IV subgroup $(\mathrm{n}=115 ; \mathrm{P}=0.011$; Fig. 5$)$.

\section{Discussion}

In the present study, PTTG1 was identified as a cancer-promoting gene that appears to serve an important role in laryngeal cancer development. The occurrence and development of Laryngeal cancer is considered to be a result of the interaction of multiple factors, and one of the most important mechanisms underlying laryngeal cancer is proto-carcinogenic gene regulation causing abnormal cell

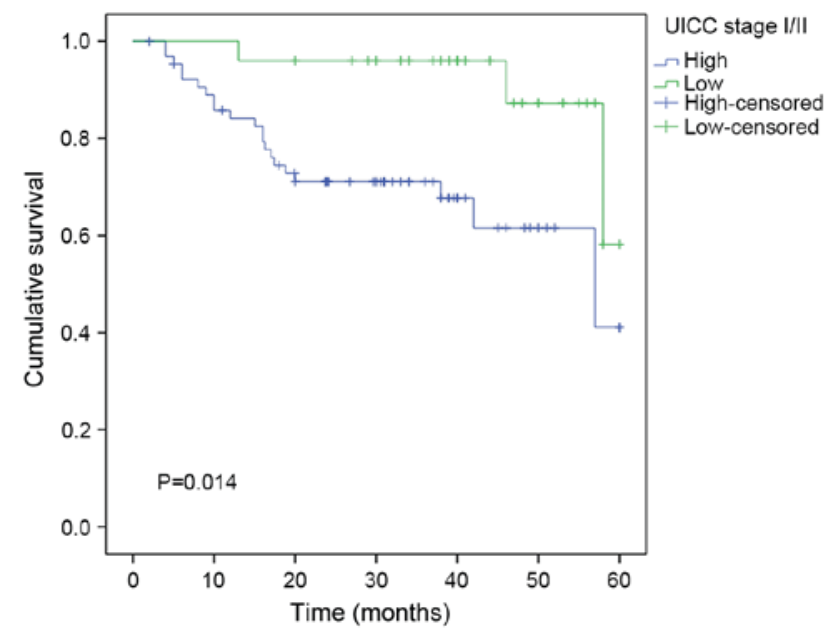

Figure 4. Kaplan-Meier analysis of overall survival according to low PTTG1 expression and high PTTG1 expression in patients with stage I/II laryngeal cancer. P-value was calculated using a log-rank test and indicated a statistically significant difference. PTTG1, pituitary tumor-transforming 1. I/II ( $\mathrm{n}=74$; high, 53; low, 21).

apoptosis and cell proliferation (12). Although substantial progress has been made in the diagnosis and treatment of laryngeal cancer, invasion, metastasis, and recurrence remain the main causes of mortality in affected patients. Worldwide, the survival rate did not significantly increased from the mid-1980s to the mid-1990s. The overall 5-year survival rate of laryngeal carcinoma was $\sim 60 \%(13,14)$, which is partly due to a lack of effective biological markers.

PTTG1 is a recently discovered gene with carcinogenic characteristics which may be independently expressed in pituitary tumor cells (4). PTTG mRNA and protein are expressed in a variety of cancer types (15-17), suggesting the participation of PTTG in tumorigenesis. Overexpression of PTTG promote cell proliferation, cell-induced transformation, and sister chromatids separation inhibition mechanisms involved in tumor formation (18), plays an important role in regulating cell growth (19). Furthermore, studies by Heaney et al $(20,21)$ and Kim et al (22) suggested that PTTG may also induce the secretion of basic fibroblast growth factor (bFGF), implicating PTTG in the promotion of tumor angiogenesis, which is necessary for tumor growth. Ramaswamy et al (6) proposed that PTTG is also closely associated with tumor metastasis, and reported that high 
expression of PTTG may be associated with tumor invasion, metastasis, and angiogenic ability.

In this study, PTTG1 expression was detected in laryngeal cancer tissues by immunohistochemistry. The results revealed that the rate of positive PTTG1 expression in the laryngeal cancer group was $88.09 \%$ (185 out of 210 patients), whereas, in normal laryngeal tissues adjacent to the carcinoma, it was $17.14 \%$ (36 out of 210 patients). Thus, PTTG1 expression in laryngeal cancer tissues was significantly higher than that in normal carcinoma-adjacent laryngeal tissues $\left(\chi^{2}=212.0198\right.$, $\mathrm{P}<0.0001)$. Additionally, the positive expression rate of PTTG1 protein was significantly higher in the lymph node metastasis group compared with the group without lymph node metastasis, in the stage III-IV group compared with the stage I-II group, and in the poorly differentiated group compared with the highly/moderately differentiated group. These results indicated that PTTG1 expression is associated with lymph node metastasis, tumor stage and degree of malignancy. It may be ascertained from these results that PTTG1 plays an important role in the processes of laryngeal cancer occurrence, development and metastasis, and may be a risk factor for laryngeal cancer.

In the process of invasion and metastasis, the degradation of the extracellular matrix (ECM) and basement membrane is a key step. MMPs are a family of highly conserved zinc-dependent incision proteolytic enzymes. MMPs can degrade the ECM into various protein components, and also degrade the basement membrane, regulate tumor cell growth, promote new blood vessel formation, and regulate cell adhesion. These processes are associated with malignant tumor invasion and metastases (23-25). The roles of MMPs in the development, invasion and metastasis of tumors are widely recognized (26). MMP-2 and MMP-9 are gelatinase enzymes, and mainly act to hydrolyze and degrade type IV collagen. They play important roles in the processes of tumor angiogenesis, tumor cell invasion and metastasis (27). Through the detection of MMP-2 and MMP-9 expression, it is possible to predict metastasis and prognosis in certain types of cancer.

Existing research shows that MMP-2 and MMP-9 are highly expressed in laryngeal cancer, and are associated with lymph node metastasis and poor prognosis $(28,29)$. In the present study, using the immunohistochemical SP method to detect the positive expression rate of the proteins, it was demonstrated that MMP-2 and MMP-9 were more highly expressed in laryngeal cancer tissues than in normal tissues adjacent to the carcinoma, and were positively associated with lymph node metastasis, degree of tumor differentiation, and clinical stage $(\mathrm{P}<0.05)$, but were not associated with age, sex, or tumor location $(\mathrm{P}>0.05)$. This is consistent with the results of previous studies $(28,29)$ and indicates that high levels of MMP-2 and MMP-9 in laryngeal cancer tissues are closely associated with the incidence of laryngeal cancer. Combined with the above description, we hypothesize that the expression of MMP-2 and MMP-9 may promote lymph node metastasis and serve important roles in the invasion and metastasis of laryngeal cancer.

Analysis of the present experimental data revealed that the positive expression rates of PTTG1, MMP-2 and MMP-9 in laryngeal cancer tissues were significantly higher than those

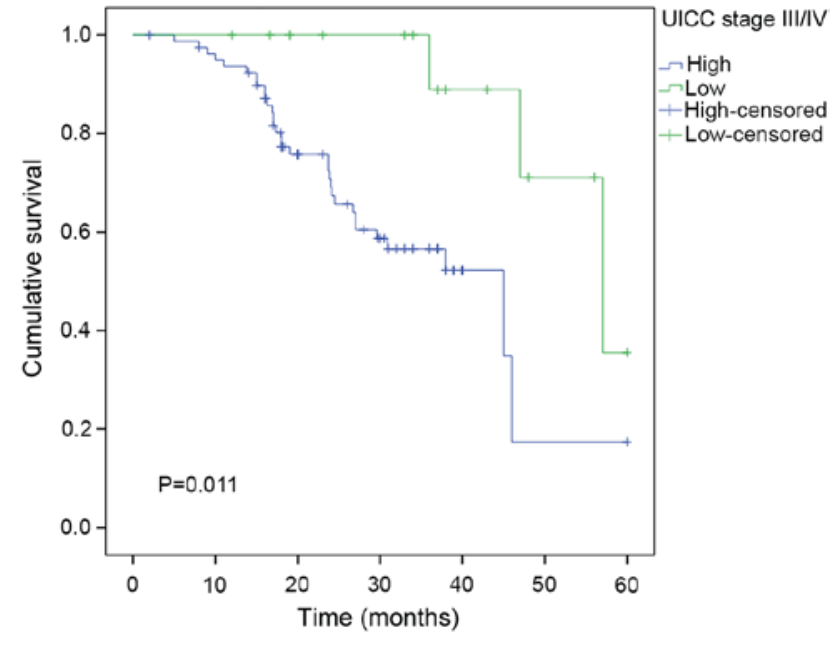

Figure 5. Kaplan-Meier analysis of overall survival according to low PTTG1 expression and high PTTG1 expression in patients with stage III/IV laryngeal cancer. P-value was calculated by log-rank test and indicated a statistically significant difference. PTTG1, pituitary tumor-transforming 1. III/IV (n=111; high, 93; low, 18).

in normal tissues adjacent to the carcinoma, with the lymph node metastasis subgroup exhibiting higher levels than the subgroup without lymph node metastasis $(\mathrm{P}<0.05)$. In addition, the expression rates of these three proteins in laryngeal cancer tissues were positively correlated with one another (Table II). The results suggest that there is a significant relationship between PTTG1, MMP-9 and MMP-2.

PTTG1 causes cancer cells to infiltrate the surrounding area, and this mechanism may involve altering the activity and secretion of MMP-2 (30). High expression of MMP-2 and MMP-9 can promote the invasion of non-small cell lung cancer (31), and interference with PTTG1 expression can reduce the expression of MMP-2 and MMP-9, reducing the invasion and metastasis of non-small cell lung cancer (32), This may be explained in that PTTG1 is a important regulatory factor of MMP-2 and MMP-9, and these three proteins serve a crucial role in cancer occurrence, invasion and metastasis.

In the present study, single-factor survival analysis results showed that patient age and sex, and tumor location had no significant effect on the outcomes of 210 cases of laryngeal cancer, whereas expression of PTTG1, lymph node metastasis, tumor stage, and degree of differentiation had marked influences on prognosis. The cumulative survival rates at 3 and 5 years after surgery in the PTTG1-negative subgroup were 85.19 and $73.68 \%$, while in the PTTG1-positive subgroup they were 41.34 and $3.52 \%$, respectively. The survival rates at 3 and 5 years in the PTTG1-positive group were significantly lower than those in the PTTG1-negative group $(\mathrm{P}<0.0001)$. Thus, PTTG1 is negatively correlated with overall survival, and the higher the PTTG1 expression, the shorter the patient survival time. This indicates that PTTG1 is an important factor in the occurrence and development of laryngeal cancer and acts to promote the invasion and metastasis of laryngeal cancer cells. Thus, it may be used as a marker of prognosis in patients with laryngeal cancer. The Cox model results showed that the positive expression of PTTG1 is an independent factor in evaluating the prognosis of patients with laryngeal cancer. 
In summary, the present study demonstrated that PTTG1 expression in laryngeal cancer cells serves a key role in tumor development and could be used as an independent biological marker for the evaluation of prognosis in patients with laryngeal cancer. PTTG1 can promote the proliferation and metastasis of laryngeal cancer cells, and the levels of PTTG1, MMP-2 and MMP-9 are significantly positively correlated. Studying the effect of PTTG1 may provide novel targets for the prevention and treatment of laryngeal cancer.

\section{Acknowledgements}

Not applicable.

\section{Funding}

The present study was supported by the Soft Science Project of Weifang Science and Technology Bureau (grant no. 2015RKX040).

\section{Availability of data and materials}

All data generated or analyzed during this study are included in this published article.

\section{Authors' contributions}

KM conceived and designed the present study, collected data, performed data interpretation and drafted and revised the manuscript. LM performed experiments and analyzed the data. ZJ performed experiments and analysis.

\section{Ethics approval and consent to participate}

The study protocol was approved by the Ethics Committee of the Affiliated Hospital of Weifang Medical University, and all participants provided written informed consent.

\section{Consent for publication}

All patients provided consent for publication.

\section{Competing interests}

The authors declare that they have no competing interests.

\section{References}

1. Papadas TA, Alexopoulos EC, Mallis A, Jelastopulu E, Mastronikolis NS and Goumas P: Survival after laryngectomy: A review of 133 patients with laryngeal carcinoma. Eur Arch Otorhinolaryngol 267: 1095-1101, 2010.

2. Shah JP, Karnell LH, Hoffman HT, Ariyan S, Brown GS, Fee WE, Glass AG, Goepfert H, Ossoff RH and Fremgen A: Patterns of care for cancer of the larynx in the United States. Arch Otolaryngol Head Neck Surg 123: 475-483, 1997.

3. Jose J, Coatesworth AP, Johnston C and MacLennan K: Cervical node metastases in squamous cell carcinoma of the of upper aerodigestive tract: The significance of extracapsular spread and soft tissue deposits. Head Neck 25: 451-456, 2003.

4. Pei L and Melmed S: Isolation and characterization of a pituitary tumor-transforming gene (PTTG). Mol Endocrinol 11: 433-441, 1997.
5. Demeure MJ, Coan KE, Grant CS, Komorowski RA, Stephan E, Sinari S, Mount D and Bussey KJ: PTTG1 overexpression in adrenocortical cancer is associated with poor survival and represents a potential therapeutic target. Surgery 154: 1405-1416, 2013.

6. Ramaswamy S, Ross KN, Lander ES and Golub TR: A molecular signature of metastasis in primary solid tumors. Nat Genet 33: 49-54, 2003.

7. Solbach C, Roller M, Eckerdt F, Peters S and Knecht R: Pituitary tumor-transforming gene expression is a prognostic marker for tumor recurrence in squamous cell carcinoma of the head and neck. BMC Cancer 6: 242, 2006.

8. Langenskiold M, Holmdahl L, Falk P and Ivarsson ML: Increased plsama MMP-2 protein expression in lymph node-positive patients with colorectal cancer. Int J Colorectal Dis 20: 245-252, 2005.

9. Edge SB and Compton CC: The American Joint Committee on cancer: The 7th edition of the AJCC cancer staging manual and the future TNM. Ann Surg Oncol 17: 1471-1474, 2010.

10. Park SS, Kim JE, Kim YA, Kim YC and Kim SW: Caveolin-1 is down-regulated and inversely correlated with HER2 and EGFR expression status in invasive ductal carcinoma of the breast. Histopathology 47: 625-630, 2005.

11. Towbin H, Staehelin T and Gordon J: Electrophoretic transfer of proteins from polyacrylamide gels to nitrocellulose sheets: Procedure and some applications. Proc Natl Acad Sci USA 76: 4350-4354, 1979.

12. Starska K, Forma E, Jóźwiak P, Bryś M, Lewy-Trenda I, Brzezińska-Błaszczyk E and Krześlak A: Gene and protein expression of glucose transporter 1 and glucose transporter 3 in human laryngeal cancer-the relationship with regulatory hypoxia-inducible factor- $1 \alpha$ expression, tumor invasiveness, and patient prognosis. Tumor Biol 36: 2309-2321, 2015.

13. Hoffman HT, Porter K, Karnell LH, Cooper JS, Weber RS, Langer CJ, Ang KK, Gay G, Stewart A and Robinson RA: Laryngeal cancer in the United States: Changes in demographics, patterns of care, and survival. Laryngoscope 116 (Suppl 111): S1-S13, 2006.

14. Carvalho AL, Nishimoto IN, Califano JA and Kowalski LP: Trends in incidence and prognosis for head and neck cancer in the United States: A site-specific analysis of the SEER database. Int J cancer 114: 806-816, 2005.

15. Ramos-Morales F, Dominguez A, Romero F, Luna R, Multon MC, Pintor-Toro JA and Tortolero M: Cell cycle regulated expression and phosphorylation of hpttg proto-oncogene product. Oncogene 19: 403-409, 2000.

16. Solbach C, Roller M, Fellbaum C, Nicoletti M and Kaufmann M: PTTG mRNA expression in primary breast cancer: A prognostic marker for lymph node invasion and tumor recurrence. Breast 13: 80-81, 2004.

17. Rehfeld N, Geddert H, Atamna A, Rohrbeck A, Garcia G, Kliszewski S, Neukirchen J, Bruns I, Steidl U, Fenk R, et al: The influence of the pituitary tumor transforming gene-1 (PTTG-1) on survival of patients with small cell lung cancer and non-small cell lung cancer. J Carcinog 5: 4, 2006.

18. Smith VE, Franklyn JA and McCabe CJ: Pituitary tumor-transforming gene and its binding factor in endocrine cancer. Expert Rev Mol Med 12: e38, 2010.

19. Pei L: Activation of mitogen-activated protein kinase cascade regulates pituitary tumor-transforming gene transactivation function. J Biol Chem 275: 31191-31198, 2000.

20. Heaney AP, Singson R, McCabe CJ, Nelson V, Nakashima M and Melmed S: Expression of pituitary-tumour transforming gene in colorectal tumours. Lancet 355: 716-719, 2000.

21. Heaney AP, Horwitz GA, Wang Z, Singson R and Melmed S: Early involvement of estrogen-induced pituitary tumor transforming gene and fibroblast growth factor expression in prolactinoma pathogenesis. Nat Med 5: 1317-1321, 1999.

22. Kim DS, Franklyn JA, Stratford AL, Boelaert K, Watkinson JC, Eggo MC and McCabe CJ: Pituitary tumor-transforming gene regulates multiple downstream angiogenic genes in thyroid cancer. J Clin Endocrinol Metab 91: 1119-1128, 2006.

23. Westermarck J and Kähäri VM: Regulation of matrix metalloproteinase expression in tumor invasion. FASEB J 13: 781-792, 1999.

24. Itoh Y and Nagase H: Matrix metalloproteinases in cancer. Essays Biochem 38: 21-36, 2002.

25. Curran S and Murray GI: Matrix metalloproteinases: Molecular aspects of their roles in tumour invasion and metastasis. Eur $\mathbf{J}$ Cancer 36: 1621-1630, 2000. 
26. Dunér S, Lopatko Lindman J, Ansari D, Gundewar C and Andersson R: Pancreatic cancer: The role of pancreatic stellate cells in tumor progression. Pancreatology 10: 673-681, 2010.

27. Parsons SL, Watson SA, Collins HM, Griffin NR, Clarke PA and Steele RJ: Gelatinase (MMP-2 and -9) expression in gastrointestinal malignancy. Br J Cancer 78: 1495-1502, 1998.

28. Christopoulos TA, Papageorgakopoulou N, Ravazoula P, Mastronikolis NS, Papadas TA, Theocharis DA and Vynios DH: Expression of metalloproteinases and their tissue inhibitors in squamous cell laryngeal carcinoma. Oncol Rep 18: 855-860, 2007.

29. Saussez S, Cludts S, Capouillez A, Mortuaire G, Smetana K Jr, Kaltner H, André S, Leroy X, Gabius HJ and Decaestecker C: Identification of matrix metalloproteinase-9 as an independent prognostic marker in laryngeal and hypopharyngeal cancer with opposite correlations to adhesion/growth-regulatory galectins-1 and -7. Int J Oncol 34: 433-439, 2009.
30. Malik MT and Kakar SS: Regulation of angiogenesis and invasion by human pituitary tumor transforming gene (PTTG) through increased expression and secretion of matrix metalloproteinases-2 (MMP-2). Mol Cancer 5: 61, 2006.

31. Lim BJ, Jung SS, Choi SY and Lee CS: Expression of metastasis associated molecules in non-small cell lung cancer and their prognostic significance. Mol Med Rep 3: 43-49, 2010.

32. Li H, Yin C, Zhan B, Sun Y, Shi L, Liu N, Liang S, Lu S, Liu Y, Zhang J, et al: PTTG1 promotes migration and invasion of human non-small cell lung cancer cells and is modulated by miR-186. Carcinogenesis 34: 2145-2155, 2013. 